\title{
Piloting the Concurrent Teaching of a Graduate Programme at Multiple Sites and its Value to The University of the West Indies
}

\author{
Stafford A. Griffith \\ Office for Online Learning \\ University of the West Indies
}

\begin{abstract}
This article reports on the benefits of a pilot at the University of the West Indies (UWI) School of Education which entailed the teaching of a Graduate Diploma in Education through The UWI's Single Virtual University Space (SVUS) that used the Zoom platform to host online classes. It facilitated concurrent delivery of courses to students at a number of sites and countries. The SVUS was an initiative of The UWI to serve, better, the needs of communities where students may not be able to access a programme delivered at a University campus. The lessons learned from the pilot informed several subsequent UWI initiatives, including the work of the Office for Online Learning which is responsible, inter alia, for expanding the concurrent delivery of the University's programmes and courses to multiple sites. The lessons learned may also be of value to other institutions seeking to deliver programmes to multiple sites through video streaming.
\end{abstract}

\section{Introduction}

The University of the West Indies (UWI) was established by Royal Charter, initially as the University College of the West Indies, in 1948. It is the Commonwealth Caribbean's premiere University, now offering undergraduate and postgraduate certificates, diplomas and degrees in Engineering, Humanities and Education, Law, Medical Sciences, Pure and Applied Sciences, Science and Agriculture, and Social Sciences. It has a student population of approximately 50,000, and graduates approximately 10,000 students annually. It prides itself for producing two Nobel Laureates, dozens of Rhodes Scholars and more than 18 current and former Caribbean Prime Ministers and Heads of State. It ranks among the top five percent of Universities globally [1].

The University now has four campuses - Cave Hill in Barbados, Mona in Jamaica, St. Augustine in Trinidad and Tobago, and a virtual campus - the Open Campus. It provides services primarily to countries of the Commonwealth Caribbean.

The University currently employs multiple modalities in delivering its programmes to the diverse communities it serves across the
Commonwealth Caribbean. In addition to face-toface delivery which is its predominant mode of delivering its programmes, it utilises online asynchronous delivery as well as synchronous video streaming using web based technologies. Prior to 2014, such synchronous delivery was limited to a few classes which the Mona Campus in Jamaica delivered to students at its Western Jamaica Campus some 110 miles (177 kilometres) from the main Mona Campus.

\section{The literature}

A number of researchers have called attention to the explosive growth of distance education in higher education $[2,3,4,5]$. It is evident that over the last decade there has been an increasing interest in distance education by educational administrators, policy makers and academics $[6,7]$.

Mallinson and Krull [8] call attention to how increased access to the internet at increased speed and reduced costs is facilitating increased access to higher education. In a 2015 article, Cavus [9] notes that "currently, internet has been preferred in education because of the technological possibilities it is providing, and its potential to reach much larger masses of people" (p. 876). More specifically, Owusu-Mensah et al. [10] have called attention to the fact that the internet has opened new possibilities for the delivery of higher education services to larger numbers of people who might previously not have been able to access a university education because of factors such as employment, marital status, family responsibilities, and distance. The online delivery of higher education services which the internet facilitates is therefore increasing access to previously underserved groups and communities.

A 2015 report on Online and Distance Education Capacity of Canadian Universities indicated that, based on the institutions surveyed, 29 per cent of all Canadian university students registered for at least one online course [11].

A subsequent Distance Education Enrollment Report 2017 noted that as of the fall of 2016, 31.6 per cent of all higher education students in the United States took at least one distance education course. The proportion of the higher education 
student body that took distance education courses had, in fact, increased each of the previous four years - 25.9 per cent in 2012, 27.1 per cent in 2013, 28.3 per cent in 2014 , and 29.7 per cent in 2015 [2].

Moller, Foshay and Huett [12] make the point that:

With such explosive e-learning growth, most colleges and universities are willingly evolving to this new environment and providing some, if not a significant portion, of their educational offerings in web-based or other nontraditional formats. Faculty at these institutions are also being asked, and sometimes forced, to evolve as well. (p. 67)

With the advances in technology, including the internet, The UWI, like many other universities in the global community sees the opportunity not only to facilitate more online courses for its conventional student population, but also to expand access of its programmes to populations that may not otherwise have been able to access university education. More recently, it sought to do so through the expansion of interactive video streaming.

Interactive video streaming is a relatively recent mode of distance education. Although the one-way video and two-way audio have been widely employed in distance education since the 1980s [13], two-way interactive video streaming is a more recent innovation [14]. It has the advantage of most closely resembling the presence of the student in the classroom [15].

In 2013, the University launched its Single Virtual University Space (SVUS) through which it would be able to delivery of courses and programmes concurrently at multiple sites. In this way, it hoped to improve the service it provides to the small island communities of the Caribbean. It was particularly concerned with reaching students who may not be able to access a programme delivered at a main campus facility of The UWI.

\section{The Pilot Intervention}

Against this background, the School of Education piloted a programme which offered the full Graduate Diploma in Education (Part 1 of the Master of Arts in Teaching [MAT] Programme) through the SVUS. This Graduate Diploma was already being delivered face-to-face to graduate students for several years. It was intended for those who had completed a Bachelor's degree in a subject specialization but did not have any pedagogical training. The Graduate Diploma in Education was an option for preparing such graduates for jobs in the teaching profession.

It required the satisfactory completion of six taught courses and a Practicum. Each taught course required 39 contact-hours of classroom engagement.
The Practicum, which involved supervised practice teaching in a secondary school over a semester, was undertaken either in a school in which the participant served as a teacher or in one approved by the School of Education.

For the SVUS option, the taught courses for the Graduate Diploma in Education were delivered using the Zoom web communications technology that facilitated the video conferencing, online meetings and chats that were all important for the online synchronous teaching-learning engagement. This technology allowed students to participate from their desktops, laptops, tablets and smart phones, whether they were at the facility where the lecturer for the course was located or at different sites in the same country or in other countries. The technology also allowed the option of recording the teachinglearning engagements which were then made accessible to participants. This was particularly helpful to those students who, for various reasons, may have missed a teaching-learning session.

Whereas the taught courses were delivered synchronously, the Practicum was undertaken in a similar way as it was for the face-to-face students. Because of the number and location of sites involved, it was not always possible for the course lecturer to serve as the Practicum supervisor. In many instances, therefore, it was necessary to identify other Practicum supervisors in close proximity to the school in which the participants did their Practicum. Training sessions were held for these supervisors to assure comparability in the nature of the supervision they provided to participants and the assessment they were required to undertake for each participant at the end of the Practicum.

This online synchronous programme was delivered for the first time between January and December of 2014 to students from four sites in three countries through concurrent interactive video streaming. This was the first full programme that The UWI delivered through the SVUS facility.

It should be noted that for nearly two decades, The UWI, and more particularly the Mona School of Education, had been undertaking asynchronous distance teaching to deliver a number of courses at the undergraduate and graduate levels to students within Caribbean countries and, to a lesser extent, to students outside this region. It should be noted too, that even earlier, in the 1980s, the Mona School of education had been using two-way audio to deliver aspects of its programmes, particularly at the undergraduate level.

The SVUS transcended these efforts and provided interactive video streaming to multiple sites and countries. The objective was to provide for engagement of students in multiple sites as if they were all in the same classroom. 


\section{Challenges}

The pilot of the delivery of the Graduate Diploma in Education through the SVUS had to cope with a number of challenges. The SVUS was little more than a concept when the decision was taken to pilot the Diploma through this facility. The School of Education embraced the rather daunting task of putting in place all that was needed to begin this pilot from January 2014, the date that was targeted. It required extensive and sustained planning and trouble-shooting over a limited time to make this a reality.

A small team of committed and devoted professionals was established to guide the effort. The team comprised persons located at two separate campuses in two countries and from the University's Regional Headquarters in Jamaica. The team members from the Mona Campus comprised the Director of the School of Education, the Coordinator of the School of Education's Graduate Studies Programme, the Coordinator of the Master of Education Summer and Online Programme, and the Options Coordinator of the School's Computer Science and Information Technology Programmes. There was one critical team member located at the University's Cave Hill Campus in Barbados - the Coordinator of the SVUS. Two persons from the University's Regional Headquarters were active participants in the team - the University's Chief Information Officer and an Educational Technologist.

The first task was to determine the number of sites at which the programme would be piloted. An appropriate advertisement was created by the team for dissemination online and through the print media in countries served by The UWI. The advertisement was intended to be exploratory and care had to be taken to avoid making commitments which could not be assured. Follow-up discussions were undertaken by members of the team with Site Coordinators of various Open Campus Sites located across countries served by The UWI as well as with senior education officials of Ministries of Education to determine which of the sites and countries were willing and able to participate in the pilot.

Through the advertisements and consultations, it was agreed that the programme should be piloted in four sites: the Mona Campus, the Western Jamaica Campus (which, as noted earlie, is a sister campus of the Mona Campus about 110 miles or 177 kilometres from the main Mona Campus), a site in St. Lucia and one in Bermuda. A total of 19 students from these four sites agreed to participate in the programme. The number of students was much smaller than anticipated. By the time the programme commenced, the number had reduced to 15. The primary reason for the low student numbers was the inability of students to meet the cost of this programme. It should be noted that this was a self- financing programme which carried a higher fee than the regular programme. The distribution of specializations for which the students opted and the sites and countries from which they came are summarized in Table 1.

There were nine students specializing in the teaching of Mathematics. While Bermuda and Mona had 4 and 3 of these students, respectively, the other two sites had only one Mathematics student each. There were four students specializing in the teaching of English Language - two each from Bermuda and Western Jamaica. There were only two students specializing in the teaching of Information Technology, one each from Mona and the Western Jamaica.

The small numbers were very challenging for the intended purpose. In some sites, no more than one student was available for a particular subject specialization and in fact, St. Lucia had only one student participating in the programme. For the Information Technology specialization, in particular, it was very challenging for the lecturers who had to deliver courses to two students only, one in each of two sites. These small numbers seriously challenged the concept of a graduate class in the typical UWI setting. However, the team was anxious to pilot the programme and there was agreement to proceed with the limited numbers. This had significant cost implications.

\section{Table 1. Number, specializations and sites of students in the pilot}

\begin{tabular}{|l|c|c|c|c|}
\hline \multirow{2}{*}{ Sites } & \multicolumn{3}{|c|}{ Specializations } & \multirow{2}{*}{ Total } \\
\cline { 2 - 4 } & $\begin{array}{c}\text { Eng } \\
\text { Lang }\end{array}$ & $\begin{array}{c}\text { Info } \\
\text { Tec }\end{array}$ & Math & \\
\hline Bermuda & 0 & 0 & 4 & 4 \\
\hline Mona & 2 & 1 & 3 & 6 \\
\hline St. Lucia & 0 & 0 & 1 & 1 \\
\hline Western Jamaica & 2 & 1 & 1 & 4 \\
\hline Total & 4 & 2 & 9 & 15 \\
\hline
\end{tabular}

As noted before, this pilot was intended to be a self-financing programme. In this regard, it was treated no differently from what was required of other UWI distance teaching programmes. It was agreed that the capital expenditure for the pilot would represent an investment to be recovered over time. However, there were major challenges in meeting the operating costs.

Critical operating costs included (i) the teaching services required which were provided by a combination of adjunct faculty and full time faculty undertaking teaching beyond their established teaching load and (ii) the services provided by technicians who had to be available to address any technical problems which may arise and to provide guidance, where necessary, to lecturers and students who may be faced with technology problems which had to be addressed immediately to ensure the smooth delivery of the programme. 
There were other costs associated with ongoing administrative and technical services which would normally have to be met from the income of the distance programmes implemented at The UWI. Since these costs were based on a single digit percentage of the income generated, there was no critical problem in addressing these. The percentage would be met from whatever the programme was able to collect as fees. The operating expenses of concern were those of the teaching faculty and the technicians. The team guiding the project was able to work out a minimum cost for the teaching staff, and much of the costs of the technicians were absorbed by the sites as part of the goodwill contribution to the pilot.

An important challenge was the readiness of the University administrative to respond to the arrangements for delivering this programme. In the first place, the Mona Campus registry and bursary did not have in place arrangements for dealing with a second semester intake (starting in January) for the Graduate Diploma in Education. Students normally register for the programme in the first semester (starting in August).

More problematic, though, was the fact that the structure for delivery of the programme required two summer sessions and this was entirely new to the University. The two summer session were deemed necessary in order to allow the students (who were generally from the teaching profession) to maximize the number of credits they could complete during their summer vacation break. This would reduce the number of credits they would need to carry during their teaching term when they would be available only in the evenings. At short notice, significant modifications had to be made by both the Mona Campus registry and the Mona Campus bursary to accommodate the registration of these students and their payment of the relevant fees. This was a factor that may have impacted the number of students who eventually registered for the programme.

\section{The Results}

Despite start-up challenges, the programme proceeded reasonably well. At the end of the January to April 2014 semester, a short survey was conducted to get a sense of how students felt about the experience of taking the Graduate Diploma in Education programme through concurrent video streaming at multiple sites. Ten of the 15 students responded to the survey. Two were from the Bermuda site, three from the St. Lucia site, three from the Western Jamaica site and two from the Mona site from which most of the lectures delivered the course. Seven of the 10 respondents were female.

Students were asked to respond to an instrument developed and administered by the SVUS Coordinator. It comprised 24 items on a five-point
Likert scale ranging from Strongly Agree to Strongly Disagree. The items were clustered under four headings or dimensions of assessment. The number of items used to assess each dimension was not uniform but varied from 12 to 6 .

The dimensions of assessment, the number of items in each dimension and students' assessment of the items in each dimension are summarized in Table 2. The mean scores for each dimension were calculated by assigning 5 points to Strongly Agree, 4 to Agree, 3 to Neutral, 2 to Disagree and 1 to Agree.

\section{Table 2. Mean ratings of students for items on the four dimensions of the assessment}

\begin{tabular}{|l|c|c|}
\hline Dimension of the Assessment & $\begin{array}{c}\text { No. of } \\
\text { Items }\end{array}$ & $\begin{array}{c}\text { Mean } \\
\text { Score }\end{array}$ \\
\hline Instructor Use of Technology & 6 & 3.63 \\
\hline $\begin{array}{l}\text { Student Perception of } \\
\text { Technology }\end{array}$ & 12 & 3.65 \\
\hline Technical Support & 3 & 3.00 \\
\hline General & 3 & 4.20 \\
\hline
\end{tabular}

\section{Discussion}

The six items under Instructor Use of Technology focussed on how comfortable the instructors appeared in using the distance teaching technology. The overall mean rating of 3.63 for these items suggests that, in the view of the students, the instructors were moderately or fairly comfortable with the use of the technology required for the concurrent teaching in the four sites.

The 12 items under Student Perception of Technology focussed on how comfortable students were with the distance teaching technology. The overall mean score of 3.63 also indicated that students were moderately or fairly comfortable with the technology with which they had to engage for classes taught at the four sites.

The three items under Technical Support were concerned with the quality of technical services provided by technicians. The overall mean score of 3.00 suggests that students did not view this dimension as favourably as the previous two.

The three items in the General dimension were concerned with three separate areas of assessment accessibility of course content/material, how timely queries/issues were addressed and whether the student would recommend the programme to others. This dimension received the highest overall rating 4.20. Given the discrete nature of the three items, it would be useful to disaggregate their contribution to the overall mean rating of 4.20 shown in Table 2.

Of the three items in this dimension, the one with the highest mean rating, 4.50, was concerned with whether students would recommend the programme to others. This was followed by 4.20 for accessibility of course content/material and 3.90 for the timeliness with which their queries/issues were 
addressed. It is important to note that despite the moderate or fair rating of the first three dimensions, students appeared to have a rather positive view of the experience - they were willing to recommend, to others, this programme which was delivered through concurrent video streaming using the SVUS facility.

\section{The Impact and Implications}

On February 5, 2014, a Recognition Ceremony was held for the first cohort of students in the Graduate Diploma in Education programme offered through the SVUS. It was held at the Regional Headquarters of The UWI, located in Jamaica. Participants from three other countries joined the Ceremony through video links. All stakeholders seemed pleased with the SVUS initiative which provided a clear alternative to the need for all students to come to the same campus or site for a "face-to-face" experience to pursue a course or programme.

The subsequent roll out of the programme benefitted from the experience of this first, pilot cohort. The lessons learned were used to improve the quality of the programme. For the second cohort, three additional areas of specialization were offered

- Science, History and Modern Languages for a total of six specializations. The number of students registered for this second offer of the Graduate Diploma in Education through the SVUS facility, more than doubled to 46. Also, students from another country, Dominica, registered for the programme, bringing to five, the number of participating sites.

The number of participants for this Graduate Diploma in Education programme, offered through the SVUS, increased to 54 in the 2017 cohort. There number of participating sites increased over time.

Table 3 shows the number of participating countries, the number of specializations and the number of students in the programme since its inception with the 2014 pilot. It shows that students from as many as eight different sites participated in the programme over those years. In the Table, "Jamaica Open" refers to Open Campus sites in Jamaica which were located in outlying Parishes in the country. In all, over the four-year period, students from three of those sites participated in the programme. Therefore, if these were to be counted separately, the number of sites participating in the programme would be 10 .

It is evident, though, that the numbers of each of the specializations remained small over the years. There were several sites where the number of students who pursued particular specializations remained as low as 1 for some years.

In both 2014 and 2015, Mathematics was the specialization with the largest total number of students across the sites, with 9 in 2014 and 16 in
2015. In 2016 and 2017, the Science specialization had the largest total number across sites with 15 students in 2016 and 14 in 2017.

In 2014, the specialization with the lowest number across sites was Information Technology with 2; in 2015 it was English Language with 9; in 2016 it was History with 1; and in 2017 it was Modern Languages with 3.

It is evident that after the pilot year, the mean number of students per specialization increased though this fluctuated. In the pilot year, the mean number of students for the specializations offered was 5.00. In the following year, 2015, the mean number per specialization rose to 11.50 . In 2016, it dropped to 6.57 but recovered in 2017 to a mean of 9.00. The increase in numbers following the pilot, though small, was helpful in addressing some issues. In particular, issues related to meeting the delivery costs were better addressed.

The School of Education sustained the evaluation initiated in the pilot to benefit, further, from the lessons learned. Based on the experience of the pilot, the evaluation instrument was revised to focus more sharply on certain areas that warranted further attention. More extensive use was also made of open-ended questions.

The feedback obtained from the evaluation each year was used to make improvements in how the programme was delivered. Most of the administrative issues were also addressed over time. The most significant administrative issues that still required attention related to the registration process of applicants. The University's registration process was not able to respond, sufficiently well, to the timing of registration for the courses in the programme. As noted earlier, the registration for the Diploma in Education offered through the SVUS was outside the normal registration cycle.

Also, a few students continued to report challenges with internet access for online participation. Such technical issues are not uncommon, especially in the early cycle of synchronous delivery of programmes by an institution. This is well illustrated in a 2017 study by Mayer et al. [16] where a survey was conducted to evaluate the experience of students who were taught in a synchronous online environment. Students pointed to a number of technical issues that impacted both their involvement in the course and their satisfaction with the course. 


\section{Table 3. Number, specializations and sites of students participating in the programme between 2015 and 2017}

\begin{tabular}{|c|c|c|c|c|c|c|c|c|c|c|}
\hline \multirow[b]{2}{*}{ Specializations } & \multirow[b]{2}{*}{ Bermuda } & \multicolumn{8}{|c|}{ Sites } & \multirow[b]{2}{*}{ Total } \\
\hline & & Belize & Cayman & Dominica & $\begin{array}{c}\text { Jamaica } \\
\text { Open }\end{array}$ & Mona & Montserrat & St. Lucia & $\begin{array}{l}\text { Western } \\
\text { Jamaica }\end{array}$ & \\
\hline \multicolumn{11}{|c|}{2014} \\
\hline Engl. Lang. & 0 & & & & & 2 & & 0 & 2 & 4 \\
\hline Info. Tech. & 0 & & & & & 1 & & 0 & 1 & 2 \\
\hline Math. & 4 & & & & & 3 & & 1 & 1 & 9 \\
\hline Total & 4 & & & & & 6 & & 1 & 4 & 15 \\
\hline \multicolumn{11}{|c|}{2015} \\
\hline Engl. Lang. & 0 & & & 0 & & 6 & & 2 & 1 & 9 \\
\hline Info. Tech. & 0 & & & 1 & & 3 & & 5 & 1 & 10 \\
\hline Math. & 1 & & & 2 & & 6 & & 7 & 0 & 16 \\
\hline Sci. & 4 & & & 2 & & 2 & & 3 & 0 & 11 \\
\hline Total & 5 & & & 5 & & 17 & & 17 & 2 & 46 \\
\hline \multicolumn{11}{|c|}{2016} \\
\hline Enq. Lang & 1 & & & 1 & 1 & 3 & 0 & 1 & & 7 \\
\hline Soc. St./Geog. & 0 & & & 2 & 0 & 1 & 1 & 0 & & 4 \\
\hline Hist. & 0 & & & 0 & 0 & 0 & 0 & 1 & & 1 \\
\hline Info. Tech. & 1 & & & 0 & 0 & 1 & 0 & 2 & & 4 \\
\hline Math. & 0 & & & 0 & 5 & 2 & 0 & 2 & & 9 \\
\hline Mod. Lang. & 0 & & & 0 & 1 & 1 & 2 & 2 & & 6 \\
\hline Sci. & 0 & & & 0 & 2 & 7 & 2 & 4 & & 15 \\
\hline Total & 2 & & & 3 & 9 & 15 & 5 & 12 & & 46 \\
\hline \multicolumn{11}{|c|}{2017} \\
\hline Eng. Lang & 1 & 1 & 1 & & 0 & 2 & & 3 & 4 & 12 \\
\hline Soc. St./Geog. & 0 & 0 & 0 & & 2 & 2 & & 3 & 0 & 7 \\
\hline Info. Tech. & 0 & 0 & 0 & & 1 & 1 & & 8 & 0 & 10 \\
\hline Math. & 2 & 0 & 1 & & 1 & 2 & & 1 & 1 & 8 \\
\hline Mod. Lang. & 0 & 0 & 0 & & 2 & 1 & & 0 & 0 & 3 \\
\hline Sci. & 1 & 0 & 1 & & 4 & 3 & & 4 & 1 & 14 \\
\hline Total & 4 & 1 & 3 & & 10 & 11 & & 19 & 6 & 54 \\
\hline
\end{tabular}


In the case of the pilot of the synchronous delivery of the Graduate Diploma in Education, it is possible that band width issues in some of the countries where sites were located contributed to the technical issues. This has, in fact, been a continuing issue for The UWI as it sought to roll out programmes through online synchronous delivery. However, the evaluation of the delivery of the courses since 2015 suggested that there were considerable improvements.

The overall improvements in the delivery of courses for the Graduate Diploma in Education through the SVUS as well as the continuing concern with matters of registration and the technology are well illustrated by the sample of comments below. These comments were provided by participants of the 2016 cohort in response to a question on the course evaluation instrument about whether there were any challenges encountered that had not yet been resolved [17].

\section{Student A}

No.

This course almost went smoothly.

Wonderful lecturer.

The Lecturer very effective in the classroom, very good methods of delivery.

\section{Student B}

No challenge with this course or lecturer. I was only faced with hard-time challenges [of a personal nature] but the lecturer did extremely well and I enjoyed her class.

\section{Student $C$}

The lecturer seemed at ease with the technology, seamlessly engaging both remote and face-to-face students effectively.

The lecture did well overall.

I enjoyed the course.

\section{Student D}

Still waiting to be registered.

Registration is a big challenge. I really don't know if there has been any resolution as yet.

It is a big, big problem.

\section{Student E}

We have not... received our acceptance package nor have been able to accept the offer of acceptance using the link provided.
Student F

I am still not registered which will be needed to complete online class.

\section{Student $G$}

Still cannot access UWILINK [The UWI online library service].

\section{Student $H$}

The lack of consistency with Zoom. We recorded only about 4 sessions on Zoom due to technical issues.

\section{Student I}

It is a new and budding program with online students and we are trying to facilitate everyone, but the online students are often times at a disadvantage with technology and engaging in the classroom discussions.

The comments of Students A, B and C are illustrative of the comments of the majority of students who participated in the 2016 evaluation of the delivery of the Graduate Diploma in Education. The experience with the programmes was quite positive.

The comments of Students D, E and F reflect the concern about the registration process, part of which involves the formal admission of students to the programme. In some instance, students started the programme before completing the formal registration. This was encouraged to reduce the potential dropout of students who had an interest in pursuing the programme but could not get their registration completed within the anticipated time.

The comments of Students G, H and I reflect the challenges some students experience with the technology for a variety of reasons. As noted earlier, much of the challenge with the technology may be attributed to bandwidth issues in the country in which the students were located.

Nazeeri [18] has pointed out that "scaling offerings through online programs or courses has become an inherent part of growth for public, private, and non-traditional colleges and universities" (para. 1). The successful experience of the pilot of the Graduate Diploma of Education, has informed the rollout of synchronous online delivery of courses and programme that will contribute to The UWI's goal of increasing the number of students enrolled in its undergraduate and graduate programmes from approximately 50,000 to 65,000 over the five year period 2017 to 2022 [19].

Following the pilot of the Graduate Diploma in Education, The UWI has initiated some "scaling" of online synchronous offerings of its courses and 
programmes, even as it sought to address the challenges that were evident from the pilot. It is clear that, based on the lessons of the pilot, the School of Education was able to increase the number of specializations offered through the online synchronously delivery of its Graduate Diploma in Education. It was also able to increase the number of sites, countries and participants that benefitted from this programme.

Based on the experience of the programme, the School of Education also initiated the synchronous online delivery of a full Master of Education programme in Early Childhood Education in 2017. This programme is being delivered to over 30 students from Belize, an English-speaking Commonwealth country in Central America. The programme is being taught through the SVUS by staff located primarily at the Mona Campus of The UWI in Jamaica. The success of this programme so far, has led to a request from the Government of Belize for the online synchronous delivery of a second Master of Education programme, his time with a specialization that would help teachers to treat, better, with students with disabilities. That programme is now being finalized for early delivery.

Benefitting from the experience of the online synchronous delivery of the Graduate Diploma in Education, The UWI, in 2016, initiated the teaching of certain core courses in its Bachelors degree programme through concurrent video streaming at its three physical campuses - Cave Hill in Barbados, Mona in Jamaica and St. Augustine in Trinidad and Tobago. Given the recency of these programmes, the University is still studying the experience with a view to rolling out a larger number of courses and programmes for concurrent delivery across campuses through the SVUS. It is expected that this will optimize the use of the available UWI teaching resources. The division and reduction of teaching load that this approach will provide, will allow faculty more time to develop new courses and extend the time they devote to research which is a critical requirement of all faculties of The UWI.

Taking into account the successful pioneering work done through the concurrent delivery of the Graduate Diploma of Education programme, The UWI has incorporated this mode of delivery as an important dimension of the work of the recently established Office for Online Learning. This Office now has responsible for the rollout of online learning across all UWI campuses and Faculties.

The recently appointed Director of the Office for Online Learning was instrumental in the management of the concurrent delivery of the Graduate Diploma in Education programme by the Mona School of Education where he served at the time as the School's Director. The Office for Online Learning is expected to guide the expansion of both asynchronous and synchronous delivery of online courses and programmes. While the considerable experience of the Open Campus in asynchronous delivery will serve as a foundation for the expansion of asynchronous delivery of courses and programmes in the physical campuses, there will be heavy reliance on the lessons learned from the delivery of the Graduate Diploma in Education in guiding syhchronous delivery of courses and programmes in all campuses of The UWI.

\section{Conclusion}

The experience of the Graduate Diploma in Education and the lessons learned were already very useful to the The UWI in a number of ways. First, in ensuing years it facilitated expansion of the delivery of Graduate Diploma in Education for a larger number of specializations to a larger number of sites, countries and participants. Secondly, the lessons learned were instrumental in the offer a full Master of Education programme delivered synchronously to at least one country in Central America from the Jamaica Campus of The UWI. Thirdly, the pilot was the foundation on which The UWI was able to build for the synchronous delivery of courses taken concurrently by students in three different countries in which the physical campuses of The UWI are located. Finally, and perhaps, most importantly, the lessons learned will be instrumental to the wider rollout of synchronous delivery of courses and programmes through the recently extablished Office for Online Learning of The UWI which now has responsibility for guiding the expansion of both asynchronous and synchronous delivery of courses and programmes by all campuses of the University.

The lessons learned from the pilot of the synchronous delivery of the Graduate Diploma in Education by the Mona School of Education evidently have far reaching implications for the rollout of online learning at The UWI. Those lessons are also likely to be of value to any institution seeking to initiate or expand the online offering of courses and programmes to meet the university education needs of various communities, including underserved communities. For many institutions, the results of the pilot may signal ways of improving cost effectiveness in the delivery of programmes through the collaboration of multiple campuses, multiple institutions and/or multiple countries to meet the needs of larger populations, including populations in underserved communities.

\section{References}

[1] THE (Times Higher Education) World University Rankings, 2019, http://www.timeshighereducation. co.uk/world-university-rankings/

[2] Allen, I.E., and J. Seaman, Digital learning compass: Distance education enrollment report 2017, Babson 
Survey Research Group, e-Literate, and WCET, Babson Park, MA, 2017.

[3] Docebo. (2016). eLearning Market Trends and Forecast 2017-2021. www.docebo.com/resource/ elearning-market-trends-and-forecast-2017-2021/, (Access Date: 10 March, 2018).

[4] S. A. Griffith. "The impact of smaller and larger online group conferences on student achievement", International Journal of Instructional Technology and Distance Education, 8 (5), 2011, pp. 67-80.

[5] Q. Li. "Exploration of collaborative learning and communication in an educational environment using computer-mediated communication", Journal of Research on Technology, 34(4), 2002, pp. 503 - 516.

[6] A. Minnaar. "Challenges for successful planning of open and distance learning (ODL): A template analysis", The International Review of Research in Open and Distributed Learning, 14 (3), 2013, pp. 81-108.

[7] J. S. Bishop and D. F. Spake. "Distance education: A bibliographic review for educational planners and policymakers 1992-2002", Journal of Planning Literature, 17(3), 2003, pp. 372-391.

[8] B. Mallinson and G Krull. "Building academic staff capacity to support online learning in developing countries", Journal of Asynchronous Learning Networks, 17(2), 2013, pp. 63-72.

[9] N. Cavus. "Distance learning and learning management systems", Procedia - Social and Behavioral Sciences, 191, 2015, pp. 872-877.

[10] F. Owusu-Mensah, J.A. Anyan and C. Denkyi. "Staff development practices of open and distance learning institutions in Ghana: The case of the distance education programme of University of Education, Winneba, Ghana", Journal of Education and Practice, 6(4), 2015, pp. 79-86.

[11] Martel, C. Online and distance education capacity of Canadian universities, EduConsillium, Montreal QC, 2015.

[12] L. Moller, W. Foshay, and J. Huett. "The evolution of distance education: Implications for instructional design on the potential of the web (Part 2: Higher education)", TechTrends, 52(4), 2008. pp. 66-70.

[13] Gossman, P. J. Comments of the national ITFS association to amendment of part 2 of the commission's rules to allocate spectrum below $3 \mathrm{GHz}$ for mobile and fixed services to support the introduction of new advanced wireless services, 2001

[14] Moore, M. G., and G. Kearsley. Distance education: A systems view, Wadsworth Publishing, Boston, MA, 1996.

[15] J. Reissleina. P. Seelingb., and M. Reissleinb. "Video in distance education: ITFS vs. web-streaming: Evaluation of student attitudes", Internet and Higher Education, 8, 2005, pp. $25-44$.
[16] G. Mayer, J. Lingle, and M. Usselman. "Experiences of Advanced High School Students in Synchronous Online Recitations", Educational Technology \& Society, 20 (2), 2017, pp. 15-26.

[17] School of Education, Mona Campus. MAT Diploma Programme Dual-Mode Session \#1 Student Evaluation Report May 2016.

[18] F. Nazeeri. "Biggest mistake universities make when going online". University World News: The Global Window on Higher Education, 513, July 8, 2018.

[19] The University of the West Indies (UWI). (2017). The UWI Triple A Strategy 2017-2012: Revitalizing Caribbean Development 